\title{
Dual-heritage households: Food, culture, and re-membering in Hamilton, New Zealand
}

DOI 10.1515/irsr-2016-0002

Received: March 3, 2016; Accepted: April 29, 2016

Abstract: Food is deeply connected to processes of re-membering, identity construction, the texturing of shared spaces, and social relationships. This casecomparative research focusses on how everyday foodrelated practices (sourcing, preparing, serving and eating) reproduce aspects of culture and communal ways of being. We will consider the food practices of three dual-heritage households who took part in a series of biographical, 'go-along', 'eat-along' and photo-elicitation interviews. Particular attention is paid to the ways in which food is intimately interwoven with familial relationships, the reproduction of hybrid ways of being, and connecting the present, past, and future.

Keywords: Food, Tradition, Identity, Re-membering, Everyday Life

\section{Appetiser}

In food-related public health research, there is a tendency to fixate on issues of scarcity, obesity and nutrition. Much of the literature on food considers pathologies such as eating disorders (Hesse-Biber, Leavy, Quinn \& Zoino, 2012), solving obesity (Levine \& Schweitzer, 2015), and imparting nutritional knowledge on the 'right' foods to eat (Voicu, Gorghiu, Anghel \& Buruleanu, 2015). The focus is primarily on nutritional values, calorie content of food, dissecting food types into micronutrients, and recommended daily intakes. Subsequently, food consumption is often reduced to the provision of fuel

\footnotetext{
*Corresponding author: Rebekah Graham, School of Psychology, Massey University (Northern), Auckland, New Zealand, Email: rebekah.graham.1@uni.massey.ac.nz

Darrin Hodgetts, School of Psychology, Massey University (Northern), Auckland, New Zealand

Ottilie Stolte, School of Psychology, University of Waikato, Hamilton, New Zealand
}

for the body and mind (Scrinis, 2008). Although issues of sustenance and nutrition are crucial topics for food research, food is also implicated in social interactions, cultural reproduction and heritage (Lévi-Strauss, 1970). We need to consider how food provides more than an instrumental means to healthy ends.

Food and associated practices play a key role at the personal, familial and inter-group processes, and in the creation and maintenance of socio-cultural identities (de Solier \& Duruz, 2013). The food we eat, the way we eat it, and who we eat it with are deeply embedded cultural practices that say much about who we are, where we are from, and what we value (Brillat-Savarin, 1826/1949). Food thus refracts cultural ways of being (Caputo, 2011). As Goody (1982) writes:

[It is] the consuming of prepared food, both the cooked and the raw, where the identity and differentiation of each group is brought out in the practice of eating together or separately, as well as in the content of what is eaten by different collectivities; this is the arena of feasts and fasts, of prohibitions and preferences, of communal and domestic meals, of table manners and modes of serving and service. (pp. 32-33)

Cuisine associated with particular class, religious and ethnic groupings, simultaneously separates and connects groups in society. People's very sense of their own identities and those of others is reflected in the multitude of foodstuffs they avoid or procure (Lévi-Strauss, 1970) and the myriad of ways in which they prepare, eat and share food with others (Bugge \& Almås, 2006). Throughout diverse groups, traditional food practices are adapted to modern-day life in sustaining a sense of heritage and difference (Kohn, 2013).

Across societies, the social practices embedding food are just as important as the food itself, in that these often reflect familiarity, shared heritage and a sense of belonging to particular social groups (Collins, 2008). Cultural events such as the evening meal are central to interplay of material objects and sociability (Simmel, 1910/1997). Food is so central to the everyday reproduction of culture that when groups move they take their food practices with 
them into new host societies (Hage, 1997). The selection of foods, preparation, composition and presentation practices, the use of utensils, seating arrangements and eating manners, all reinforce social bonds and reproduce aspects of culture (Simmel, 1910/1997). The ways in which people reproduce their membership within particular groups through the procurement, preparation and consumption of food are of key interest in this research. This article explores the multitude of ways in which food is woven into the relationships and identities enacted in three dual-heritage (mixed migrant and indigenous) households in New Zealand today.

Actor-Network Theory (Latour, 2005) provides a useful theoretical framework for exploring the social, material and relational aspects of food. Specifically, ActorNetwork Theory considers all objects in our lifeworlds to be actors indisputably connected to our social and relational networks (Latour, 2005). Human beings are said to constantly use material objects, such as food and associated paraphernalia, to signify and solidify social orders, relationships, shared practices and identities across time (Latour, 2013). The division between active human beings and passive material objects becomes blurred as material objects are worked upon, practiced, enacted and re-enacted in our everyday lives. Further, the blending of distinctions between people and material objects in Actor-Network Theory is particularly salient, given that food is consumed and in the process becomes physically inseparable from us.

We are particularly interested in the ways in which the visceral nature of food can transport participants through time and space, (re)connecting them to people and place(s) no longer present in their current lives. Through processes of re-membering (Myerhoff, 1982:111), we explore how food traditions cultivated through distant past experiences can be rendered proximate in the present. An example of this is when the former child (now adult) uses an old recipe book to (re)enact a cooking practice and thus re-member the (grand)parent who has passed away. Here, the concept of re-membering invokes more than the cognitive process of recalling such specific events in the form of mental representations. Rather, re-membering invokes the material, embodied and emplaced nature of group membership(s), social practices, and engagements through which people re-join or embed themselves within groups and in doing so reproduce culturally-patterned traditions (Pickering \& Keightley, 2013). Through processes of re-membering time can be compressed, slowed down, or sped up (Latour, 2005). As people prepare a dish in the manner reminiscent of time spent with a grandparent, they (re)connect with relationships from the past in the present, reproducing heritage across generations, and passing on cultural knowledge to future generations. In this way, re-membering involves the material (re) construction of memories and familial ties through the repeating of food practices from the past, which entangle individuals within traditions from another time (Pickering \& Keightley, 2013).

Familial food-related memories and traditions are also regularly anchored in specific familial objects, giving these broader socio-cultural significance in the re-membering of who one is and where one comes from (Olsen, 2003). For example, we will document how, through the processes of re-membering, recipe books, particular kitchen utensils and dishes are transformed into objects of remembrance and repositories for family tales that invoke a sense of connectedness to those present and past (Serres \& Latour, 1995). A particular dish becomes an 'artefact of culture in the making' (Kohn, 2013:68), a cultural repository for the reconstruction of belonging and the folding of traditions into complex social geometries of food.

\section{Recipe for the present study}

We drew from an ethnographically-orientated approach that foregrounds the utility of case-based research (Hodgetts \& Stolte, 2012) and emphasises the importance of doing research within the context of participants' everyday lifeworlds (Small, 2009). The case-comparative method proved ideal for considering the food-related practices of three households, or cases, within the city of Hamilton, New Zealand, and the broader landscapes within which these practices were located. After all, processes of re-membering that are anchored in everyday food practices often occur in mundane spaces such as kitchens and supermarkets.

The three cases were constructed through a series of semi-structured interviews. These included the use of mapping, participant observation, photo-elicitation (Harper, 2002) and go-along (Carpiano, 2009) techniques in three phases. These phases enabled us to explore how food flows into, around, and out of the home as it is sourced, stored, prepared, eaten, and shared. Phase one involved the lead author conducting a sit-down, semistructured interview with a key informant from each household. These interviews, conducted in participants' homes, served to introduce the research topic and initiated our exploration of their food-related practices. Phase two involved participants photographing their 'world of food' over a one-week period. The resulting images then formed the basis for a photo-elicitation interview. In phase three 
'shop-along' interviews were conducted, where the first author accompanied household members as they engaged in their regular food-sourcing routines within Hamilton City. Based on the go-along technique (Carpiano, 2009), these interviews entailed accompanying and observing participants, asking questions, listening, and actively exploring participant practices as they moved through and interacted with their landscapes of food procurement (Kusenbach, 2003). In conjunction with the shop-along, participants marked on a map the physical location of their home and stores visited. This provided a representation of physical locations, creating an opportunity for participants to express their perceptions of place. Combined, these interview-based techniques enabled the exploration of the often taken-for-granted food-related rhythms of everyday life, adding depth to the construction of each case (Hodgetts \& Stolte, 2012).

As social and cultural aspects surrounding food are of interest in this research, we selected dual-heritage households within which intimate partners bring their own particular food preferences into the home to create hybrid traditions. We explored how household members seek to (re)create previously taken-for-granted practices, foregrounding the relationship between food, culture and heritage. The analytic strategy involved drawing from features unique to each case in order to build an overall interpretation that spans the three cases (Small, 2009). In exploring socio-cultural processes central to food in these households we drew on specific, concrete examples. In doing so, we invoked Lévi-Strauss' (1966:17) concept of the researcher as bricoleur. Our approach involved interrogating the meanings of particular images and scenes by 'using and repurposing the artefacts of memory, the stories of the past, and the drifting of history' (Knepper, 2006:85). Following Simmel's (1910/1997) classic seminal analysis of the meal, we utilized his principle of emergence (1903/1964) by moving out from specific observed instances to explore aspects of the broader socio-cultural universe at play in the sourcing, preparing and sharing of food by the three households.

\section{Main course}

In keeping with the case-comparative method, each household provides the focus for a particular section of our analysis. First, the Marton household is drawn upon to illustrate issues of re-membering through the preparation and consumption of particular dishes associated with specific events. Next, the Barrett household offers additional insights into processes of hybridity and the continuation, integration and reproduction of cultural values through the enactment of food routines. Finally, the Linton household illustrates the concept of dis(re) membering and the disruption of food traditions that can occur for those who seek to disassociate themselves with negative aspects of their childhood food experiences.

\section{Marton household: Migration and re-membe- ring tradition}

The Marton household is comprised of Amy, Paul, and their two daughters aged ten and twelve. A migrant from Singapore, Amy has spent over two decades living in Hamilton, New Zealand. Paul is of Māori descent ${ }^{1}$. In this section we focus on the ways in which Amy actively constructs her identity as a New Zealand caregiver in the Singaporean diaspora. This case exemplifies how food and identity are deeply connected with different places and ethnic backgrounds. For migrants, the consumption of foods associated with home creates a tangible connection to their heritage (Choo, 2004). It is worth nothing that culture and food geographies cannot be neatly tidied away into a homogenous, bounded, separate 'thing'. Instead, they are 'messy, changing, non-essential, heterogeneous, embodied, diasporic, hybrid, everyday, leaky, viscous 'cultural' practices' (Cook, 2008:824). It is these messy, embodied, leaky everyday practices that we seek to explore here.

Daily routines, such as the preparation of meals, provide a way for migrants to maintain cultural links to their homeland while forging new hybrid identities. In negotiating her sense of self today, Amy talked at length about the many food differences between New Zealand and Singapore. Conversations around different cuisines reveal how food is positioned as an actor within the negotiation of everyday understandings of people's situations and selves. Differing approaches to food and taste regularly come to the forefront of discussions whenever Amy meets fellow Singaporeans:

\footnotetext{
... if I meet a fellow Singaporean now, without doubt, within the first five minutes they go 'Oh, do you miss the food?' And we can talk about it for the next half an hour to an hour, just food. And they laugh and the conversations always goes 'Oh, Singaporeans always talk about food!' And it's true. It is so true.
}

Here, references to food provide a means of connecting with what it means to be Singaporean in a new place. Engaging in discussions around food offers Amy a way of maintaining her identity as a Singaporean New Zealander.

1 Māori are the indigenous people of New Zealand 
The cooking and sharing of food also offers a way for diasporic communities to re-member home (Blunt \& Dowling, 2006). Food provides 'a clear intimation of familiarity in that people know what to do with it, how to cook it, how to present it and how to eat it, thus promoting a multitude of homely practices' (Hage, 1997:109). The engagement in social practices with friends and family makes familiarity with objects such as food significant (Collins, 2008). The banter between Amy and her father below represents how images of familiar foods are used to embody familial connectedness and a shared cultural heritage:

So that was my mangosteens. I just took a photo of that to show my Dad. Again, food: 'Hey look what I found! Click! Email!' And Dad, interestingly, Dad emails us all the time, mainly recipes 'Hey, who thinks they're going to make this for me?' That kind of thing. 'Hey, look what I found, this looks yum.' Or restaurant reviews. A lot of those. So my family is really food based.

Above, food is positioned as an actor through which the love, care and concern that these family members have for one another is expressed. It provides a sense of shared identity as 'us'. Emailing an image of food becomes shorthand for "I'm thinking of you" or "wish you were here". The physical act of (re)creating and consuming a favourite dish reflects Amy's care for her father, and bridges the sensory gap between here and there (Collins, 2008; Hage, 1997). Food offers tangible sensations and reminders that provide migrants with a relational connection to their cultural home, and thus the act of eating specific dishes becomes an act of re-membrance (Choo, 2004; Collins, 2008).

Figure 1 shows a selection of the traditional treats that Amy makes for her family for Chinese New Year: pineapple tarts, fruit buns, and almond biscuits. Amy prefers to make these delicacies the traditional way that her mother taught her. This results in a taste that is more familiar with her childhood memories of home-made treats. Amy explains:

My Mum, she used to make these and now I do. So these ... are food for cultural celebrations and stuff. So that's the goodies that I make ... Things like Chinese New Year, um you know, pineapple tarts ... when we were in Singapore you'd just buy the whole pineapple and then you'd grate the whole thing, and now you just buy it in a can ... Even in Singapore they're getting lazy and they just buy it or get it pre-made which just is not the same. Yeah. And so I try and still do the traditional, cause it's nicer.

This quote offers insights into the sociocultural roles that Amy has adopted as a mother, daughter and caregiver in New Zealand. She also acknowledges that in Singapore too,

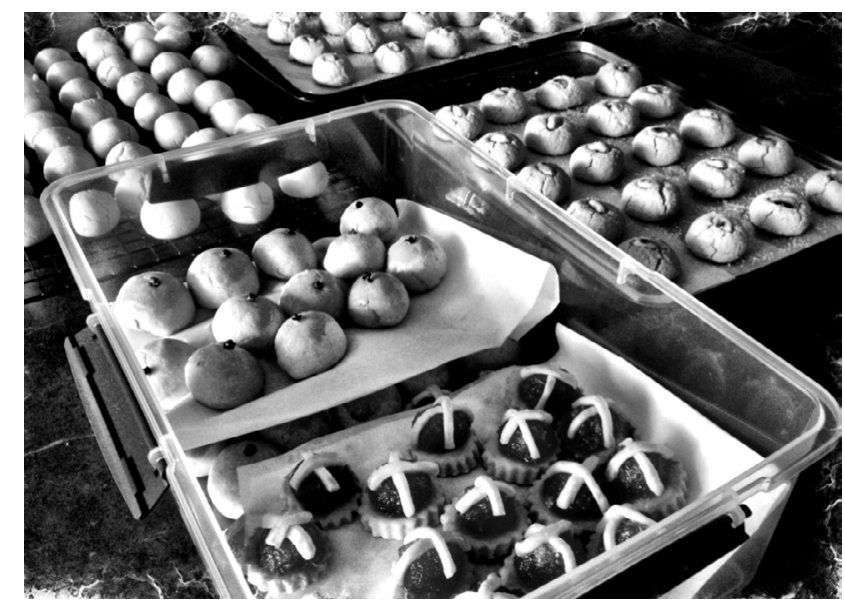

Figure 1: Traditional Chinese New Year treats

people are increasing their use of convenience foods. The Singapore that Amy remembers from her childhood is the cultural home she seeks to reconnect with through eating traditional Chinese New Year treats. The preparation and eating of such specific foods (re)connects the past with the present (Supski, 2013), prompts Amy to look forward to certain events, and 'stills' time by recreating past occurrences (Seremetakis, 1996:23-44).

Amy has also continued her mother's tradition of baking cakes for birthdays and special occasions. The process of creating and decorating cakes is time intensive and involves the sourcing of specialist ingredients. When considered within the context of Amy's busy life, the time and effort required to source, make, and decorate these special treats enhances their status as a gift of care ( $c f$., Hodgetts, Hayward \& Stolte, 2013). The special nature of baking and decorating cakes sets it apart from the mundane everyday routines of the Marton household, elevating the time spent from routine to ritual. Amy takes time to create gifts of care that reflect her identity as a caregiver. In doing so, she re-connects with her memories of her late mother, ensuring that her mother's legacy of giving is recreated in the present day. Amy's daughters also enjoy the special time of baking and decorating cakes. Figure 2 shows Amy's daughters using icing nozzles to decorate cupcakes. The quote below reveals how baking has become a link connecting Amy to her mother and her daughters:

Learning from my Mum; my kids are doing the same thing. So they are watching me and they wanted to make the cupcakes and play, because they saw me using my nozzle, so they wanted to do it. So that was me guiding them. And then, for Mothers' Day I went out all day and when I came back they had made me cake balls. All by themselves, just from watching me. They made the cake from scratch, they made everything from scratch. So, I'm passing on what I've learnt from my Mum. 


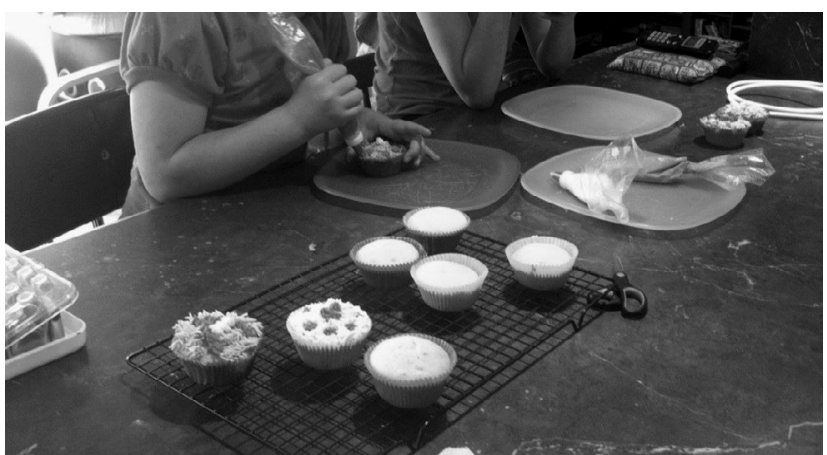

Figure 2: Decorating cupcakes with icing

This transference of cake decorating skills across generations provides an example of the way in which re-membering and cultural values are integrated into specific material practices through which enculturation occurs. The process of learning (and enjoying) cake decorating highlights that memory is not simply a collection of discrete past episodes or a reflection of fixed notions of culture. Rather, re-membering is an on-going interpretative process of reconstruction, where memories are located within everyday experiences and specific locales (Cubitt, 2008). The rituals depicted in Figure 2 manifest cultural ideals of giving, familial participation, sustaining memories of lost loved ones, and of using food as a vehicle for familial care. The preparation and consumption of specific foods represents one way in which familiarity can be recreated (Collins, 2008). The transference of food traditions to the next generation becomes the form through which memories of a past somewhere else are mediated within the present somewhere new (Fortier, 1999). Amy's Singaporean ethnic heritage is kept alive within the family and into the future. Even where cultural memories of places and sites have been fragmented, knowledge of specific dishes may still be retained and, when prepared and consumed, act as repositories of heritage (Dodson \& Gilkes, 1995).

\section{Barrett household: Hybridity and familial harmony}

The Barretthousehold comprises of threegenerations: Aran and Tineke, their baby daughter, Tineke's sister Sandra and their mother Paiya. Paiya is a migrant from Sri Lanka and has lived in New Zealand since her daughters were pre-schoolers. Consequently, Paiya's daughters (Tineke and Sandra) identify as New Zealanders of Sri Lankan descent. Aran (Tineke's husband and Paiya's son-in-law) identifies as New Zealand Māori. In this household, food is the vehicle through which links to cultural heritage and harmony in relationships are maintained. More than just a chore, the provision of food re-enacts shared underlying cultural values of hospitality, care, and connectedness to others. In particular, acts of hospitality provide a way for this household to solidify their social relationships, enact cultural values and engage in processes of identity construction and re-membering.

Social groups create, transform and reproduce cultural representations of foods that make them distinctive from other societies (Lévi-Strauss, 1970; Mintz \& Bois, 2002). Paiya's identity as Sri Lankan is strongly connected to the distinctive tastes of the curry of her childhood. She regularly cooks curry and rice for the family's evening meal. Rice is an important part of everyday life within many South East Asian cultures (including Sri Lanka). Despite being a staple food, rice has significant social status and ritual importance (Smith, 2006), contributing towards cultural identities (Senauer, Sahn, \& Alderman, 1986). It is assumed that rice will be served at most meals. Rice is as much a cultural marker as the flavours and tastes of (Sri Lankan) curry. Aran actively supports his motherin-law's (Paiya) culturally-patterned food preferences, and he has happily embraced eating curry and rice as part of life within this household. Aran is responsible for the family's regular supermarket shop, and ensures pre-cut meat is purchased in order for Paiya to more easily prepare curry dishes for the family meal:

This is what I normally get [points to meat purchases from butcher's shop], just a bit of everything ... 2 beef, [brisket] 2 pork, 2 lamb, 2 chicken ... Every now and then they'll have a special. If I see the sign I'll go in and buy some ... Normally at the meat shop the meat comes like, they've got meat already chopped up and stuff ... It's already cut so you just make the curry and just chuck that in.

Aran's meat purchases are at one level simple and routinized. At another level this seemingly simple act of cooperation facilitates the enactment of Paiya's cultural food traditions through which her identity links to Sri Lanka are maintained and transmitted across generations. In cooking for the family, with meat sourced by Aran, Paiya both (re)creates her food traditions and transfers these to other members of the household.

The Barrett household routinely eat the dinner meal together at the end of their working day. In contrast to breakfast (an individual, rushed event), and lunch (primarily eaten at work), eating the evening meal is viewed as an important part of the family's everyday life. The evening meal represents a time where, despite their busy lives, important familial and social routines are enacted. As with many urbanites, the cultural importance of breakfast and lunch has diminished, and dinner 
has become the most socially important meal (MellinOlsen \& Wandel, 2005). The value this family places on the evening meal is evident in the many photographs of dinner dishes taken by household members. Ingredients, food preparation, and final dishes were all photographed, as shown in Figure 3.

Food consumption in the form of an evening meal serves to socially construct the Barrett family as a hybrid Sri Lankan-New Zealand household and to cement the relationships within it (DeVault, 1991). The dinner meal provides a context whereby connections and relationships are reaffirmed. The sharing of a meal as a family becomes a metaphorical representation of the sharing of domestic spaces and culturally-patterned lives within the household.

Within this household, food embodies deeply held values and beliefs around hospitality and care (Mintz \& Bois, 2002). Particular practices of hospitality are indicative of cultural heritage (Marsden, 2012), and go beyond the mere physical provision or offering of food to guests. Rather, hospitality requires freely giving time, attention, consideration and effort to ensure that guests are welcomed and made comfortable (Jansen, 1997). In the Barrett household, these practices are exemplified in the food images (see Figure 4) from a birthday dinner celebration at their family home. Invited guests are provided with a variety of plentiful dishes to eat, including those depicted in Figure 4, which are: (clockwise from top left) rice, steak, and lamb curry; vegetable bake; close-up of the lamb curry; a chicken dish; seafood salad; lamb chops and sausages.

The invitation to guests to celebrate a birthday, along with the provision of more than enough to eat, articulates the complex relationships between food, the domestic space of the home, social bonds between host and guest, and mutual obligations (Shryock, 2009). In this instance, the Barrett family hosts wider family members in acknowledgement of the close and reciprocal nature

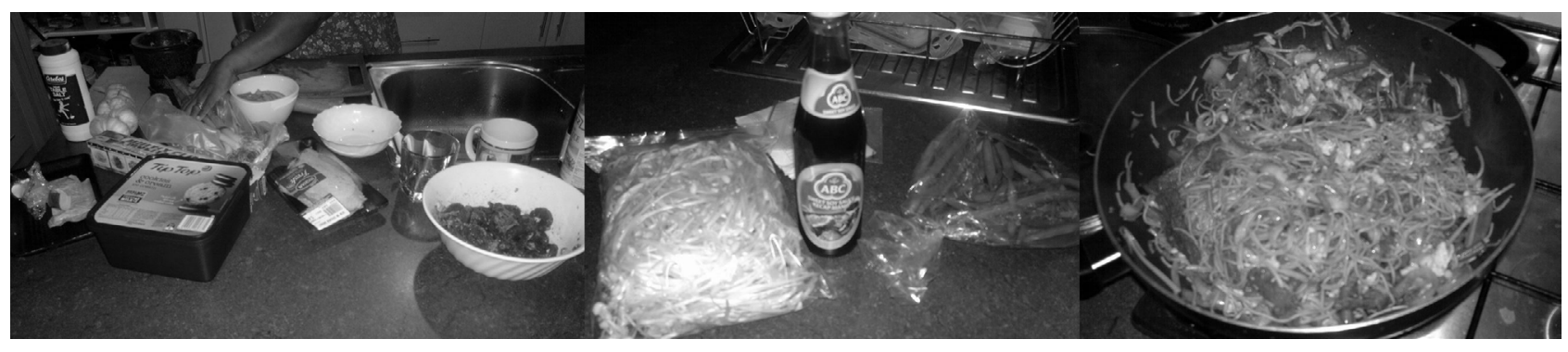

Figure 3: Dinner meal and ingredients

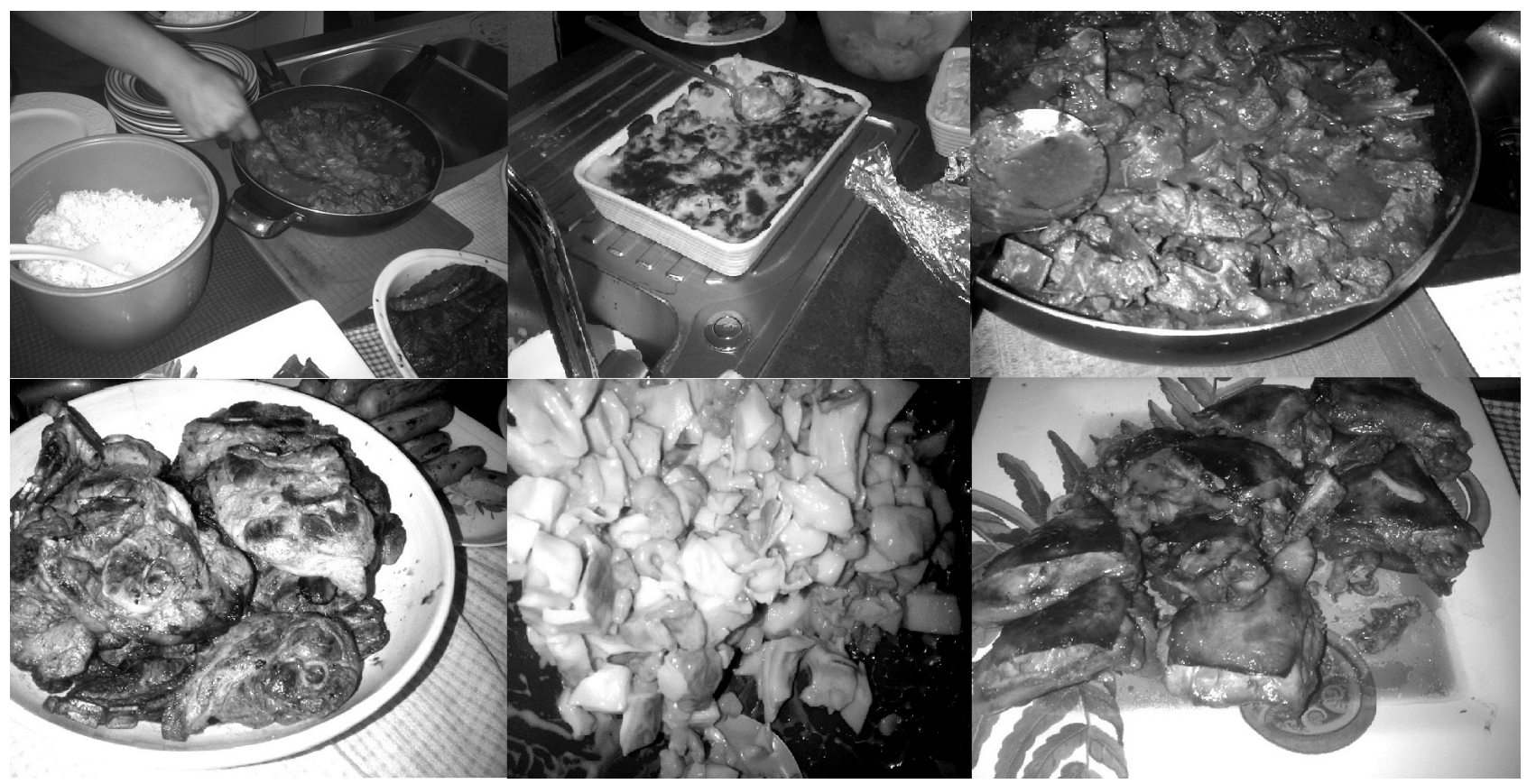

Figure 4: Selection of birthday dinner dishes 
of their familial bonds. Further, caring for their guests and ensuring that they have plenty of food strengthens their shared Sri Lankan-Māori identity. The enactment of hospitality is a taken-for-granted aspect of their everyday life and articulates their shared values, as shown in the following exchange:

Aran: I guess even when people come over, we sort of like make food different to what we normally make.

Tineke: Like we'll go out of our way to make sure we have a proper dessert, or something, not just chocolate. [...]

Paiya: And there will be a lot of variety ... like for barbeque we also make rice, curry, and

Aran: Yeah, instead of just making the normal you know meat and vegetables and rice [others agreeing] we'll make a couple of different vegetables and stuff. [...]

Tineke Actually one time Mum invited one of her friends to dinner, just one person, and she made so much food.

Sandra Like when someone else comes Mum always makes lots of different dishes.

Tineke And it's just like so much, so much variety, to make sure that they go away satisfied.

By ensuring that guests are fed, welcomed and looked after, the food-related practices of this household enact the Māori cultural value of manaakitanga (Gilgen, 2008). Manaakitanga foregrounds the importance of paying heed to the needs of other people as a basis for building reciprocal and trusting relationships, and is implemented through reciprocity, hospitality, kindness, and the provision of food (Johnson, Hodgetts, \& Nikora, 2013). Similarly, the performance of hospitality is central to the identities of many South Asian peoples (Marsden, 2012). Amongst South Asian cultures the provision and consumption of food is considered essential for any social gathering (Mellin-Olsen \& Wandel, 2005). The valuing of hospitality in both these traditions is brought forward into the present, connecting both providers and recipients of care with past generations (Cash, 2013). Through engaging in food events such as birthday celebrations, the Barrett family establishes concordance between the traditional practices of two cultures and their contemporary everyday life. In the process, deep links are (re)invigorated between their personal and collective ways of being (Cash, 2013). Different cultural values that are compatible are reproduced in the hybrid enactment of new combinations of foods that are central to the Barrett household.
The photographs and associated commentary reveal how aspects of both cultures within the household are represented on the dinner table. The dinner table materialises the combined heritage of the hosts and contributes towards harmonious social relations within the home. The provision of Sri Lankan curry and rice alongside steak, lamb chops and sausages evokes memories of past events, and celebrates contributions from both cultures. The weaving together within the Barrett household of differing food traditions provides us with a tangible illustration of the ways in which cultural identities can be hybridic, fluid and interconnected through food. The compatibility of the underlying values from the two cultures leads to a new hybrid (third) space for their children.

\section{Linton household: Dis(re)membering and the creation of new traditions}

The third case considers the Linton household: Evan, Katarina, and their two boys aged eight and eleven. Katarina identifies as Māori and Evan as a European New Zealander. Katarina's early years were spent with her birth mother, whom she refers to as Karen. Katarina reserves the use of the word Mummy - and its attendant association with love and affection - for her paternal grandmother who raised her from the age of seven. Katarina's early childhood memories are characterised by food insecurity. Although the days of food insecurity are long gone, the memories of hardship remain vivid, impacting on her sense of self, her food-related decision-making, and her identity as a mother.

Food is not abundant for everyone, nor is re-membering necessarily a desired practice. Here, we explore the concept of 'dis(re)membering' (Landzelius, 2003:195,211212) through the way in which Katarina distances herself from her birth mother by distancing herself from specific foods and related practices. Certain foods that Katarina's birth mother provided are so intertwined with deprivation that Katarina remains unable to eat, cook or serve these foods, as shown in the following humorous exchange with her husband Evan:

Evan It's delicious! It's bread and jam on a little bit of cream. [Laughter] It's because I don't have the psychological hang-ups so I can think about the flavours! [Laughter].

KatarinaIt's true! Whereas he just thinks of the flavour and goes 'Oh this is delicious' and I go, 'I remember being in the dark eating this with no light bulbs!' 
The same dish can have varying meanings for different people who grew up in different circumstances within which specific foods are encountered. For Evan, the association is one of enjoying bread and jam, whereas for Katarina the dish evokes unpleasant memories. It is not just the material aspect of the food that Katarina is responding to here, but the association between taste and re-membered feelings of deprivation. The experience of food evokes recollection through emotional and physical sensation (Holtzman, 2006). Taste, smell and texture are all highly visceral, and have the capacity to embody memories, bringing them forward from the past into the present. Here food acts as a vehicle for specific memories and feelings: particular tastes, textures and flavours instantly transport Katarina back to being an unhappy, hungry child who is eating bread and jam in the dark. Avoiding such foods provides a way for Katarina to dis(re)member the unpleasant parts of her childhood. Landzelius (2003: 195) applies the term 'commemorative dis(re)membering' to explain people's attempts to collectively minimise painful cultural memories of events. In this paper we observe how Katarina's attempts to dis(re)member are highly personal, involving her daily practices and routines in relation to food. Certain foods are literally, as well as metaphorically, dis(re)membered as Katarina seeks to leave behind a food landscape that reflects poverty, hardship and insecurity.

The well-being of households is intimately connected with issues of food (in)security (Belsky, Moffitt, Arseneault, Melchior, \& Caspi, 2010). For children, food insecurity can be associated with lasting emotional distress (Belsky et al., 2010). As noted earlier, much of the research on food insecurity focusses on easily quantifiable aspects such as household income levels (Ramsey, Giskes, Turrell, \& Gallegos, 2012), nutritional values (Webber, Sobal, \& Dollahite, 2010) and physical health (Drewnowski \& Specter, 2004). Less easily quantifiable aspects, such as feelings of security, being loved, and a sense of care are more challenging to measure and explicate. Yet, as Katarina states, it is these more intangible elements that are salient for her: 'But she was also an abusive mother [birth mother]. So it wasn't, you know, poor food cooked with love, it was poor people's food cooked with hate.' For Katarina, it is the perceived absence of psychological care that is materially manifested in the meals (un)provided by her birth parent. The association of certain foods as markers of a lack of parental care is such that, in order for Katarina to adequately express her love and concern for her own children, it is necessary for her to make a conscious effort to provide an abundance of quality food. Serving the dishes of her own early childhood is equivalent in her eyes to not providing for her children:
... a lot of those types of food just make me feel like I've failed as a parent if I feed them to my kids. Because, I just think, you know, 'No, we can afford better than that!'... It goes back to the feelings of, as a child, I always said 'I'm not going to be like Karen [birth mother]. I'm not going to do that ... I can't not give my children what they want to eat because otherwise I'm withholding food from them and that's like Karen. It's more not wanting, you know, not wanting to repeat aspects of my childhood and it often comes out in food.

For Katarina, the materiality of having sufficient and lovingly prepared food to eat is a tangible expression of care. In ensuring that her children have material and emotional comfort through the provision of food, Katarina is creating a new tradition for her children. Food has long been used as a way of demarcating social groups and identifying social classes (Goody, 1982). Katarina's determination to provide a better life for her children is intertwined with changes in her social class. Her determination not to be like her birth mother is the stated primary force behind Katarina's rejection of the foods she associates with poverty and neglect.

Not all foods from Katarina's childhood are dis(re) membered. Re-creating dishes from her grandmother's cookbook (see Figure 5) showcases one of the ways in which Katarina re-members a more positive time in her life, when she went to live with her paternal grandmother at age seven:

I've got Mummy's [paternal grandmother] cookbook [see Figure 5]. It was like the thing I wanted from her when she was sick and, you know, dying and stuff. She had a cookbook that was written in ... all of Mummy's handwritten recipes. So I like making things from that ... ... you couldn't beat Mummy's feijoa2 sponge ... Now, you know, I like to make some of the things that Mummy used to make.

These positive associations with food, as noted by Katarina, are anchored in the materiality of the care-worn and hand-written nature of the cookbook (Figure 5). For Katarina, this book functions as a social actor (Latour, 2005) calling her into particular food-related memories that are associated with a heritage transmitted to her by her Mummy. Cooking recipes from this cookbook, together with the aromas and sensations of cooking particular dishes, re-creates feelings of warmth and love. Ironically, as a child, Katarina strongly disliked preparing feijoas for baking, and would loudly protest at having to participate in the preparation rituals involved. Now, however, cooking

2 A sub-species of guava that is widely found in many residential gardens throughout New Zealand. These trees bear prolific fruit with a short shelf-life, requiring expedient eating and/or processing. 
feijoa sponge cake transports Katarina back through time to a more fondly re-membered past (Latour, 2005).

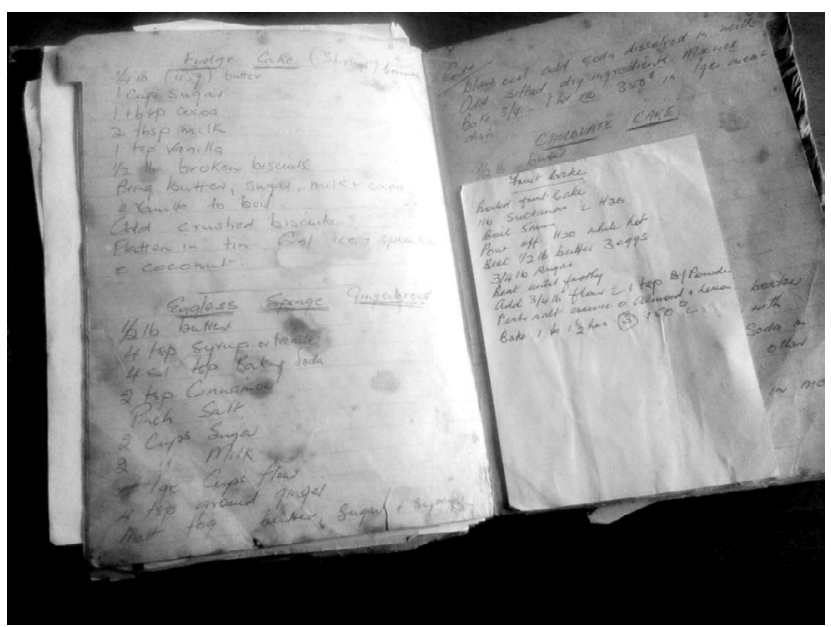

Figure 5: Cookbook with handwritten recipes

Using an old tatty cookbook transforms the mundane activity of food preparation into a ritual where Katarina re-enacts memories of being cared for by her much loved grandmother. The metonymic nature of the cookbook transcends its materiality as an object in a physical world (Olsen, 2003), embodying Katarina's loving connection with her late grandmother (Morgan \& Pritchard, 2005). The cookbook contains Katarina's memories within its pages and is representative of positive past experiences. Beyond this, using her cookbook transports her through time and space, creating a way for her to (re)enact and (re)affirm relational links (Latour, 2005). Briefly, this case exemplifies how re-membering is not always a positive experience and is not always embraced. Where memories are painful people may seek to dis(re)member. This is evident in Katarina's efforts to be a caring mother and to disrupt her history of poverty by providing an abundance of food. However, not all aspects of Katarina's past are dis(re)membered, as evidenced by her treasuring of a material object that is her grandmother's much-used cookbook. The use in the everyday of such a mundane and careworn item belies its metonymic function as a sacred object of re-membrance.

\section{Dessert: Points to take away}

While necessary for physical survival and health, food is also an important part of the social world. Food acts as a tangible, visceral nexus for the enactment of relational ties, heritage, identity and class. Actor-Network Theory (Latour, 2005) is useful in orientating us towards the connections between food, material objects, cultural practices, and the people within the networks that populate lifeworlds. Food and related objects are key actors in everyday life. In these three households, we move beyond specific practices such as preparing diced meat for the creation of a curry, into the connections such acts have with wider sociocultural practices and the social patterning of contemporary urban life. The taken-for-granted aspects surrounding the preparing and eating of food make visible the often invisible systems and structures that make up everyday existence (Pickering \& Keightley, 2013). It is by engaging in food-related practices that people can (re)connect to their cultural heritage and (re)create a sense of belonging.

Specific dishes associated with one's parents or grandparentscan also work to bridge time and space (Serres \& Latour, 1995). In preparing such dishes one can relive a relationship with, for example, a parent who has since passed. The folding of time and space in such instances also reveals re-membering as a material practice through which people renew wider group memberships, cultural traditions and relationships. Particular relationallytextured material objects, such as handwritten cookbooks or traditional Chinese New Year treats, are representative to participants of other places and different times. These items both anchor and transport our participants through time and space (Casella, 2012; Duff, 2012), bringing people and places that may be considered to be very far away near once more (Jóhannesson \& Bærenholdt, 2009).

We have documented how the food our participants eat is mobilised in the construction of hybrid, fluid, and reflexive identities, such as in the overlapping of Singaporean, Māori, Sri Lankan, European and New Zealand identities. In this research, each family group negotiates salient aspects of the heritage groups with which they have an affinity. In doing so, they effectively create a third space, within which new, hybridic identities are created and maintained. As family members articulate and negotiate the food-related practices of their household, they are determining the aspects of their cultural heritage that they wish to maintain and/or discard.

Food-related health research often overlooks the socio-cultural significance of the ordinary, the mundane, and the familiar (cf., Latour, 2005; Olsen, 2003). In addition, the framing of food solely within biomedical notions of health ignores the inherently cultural and situated aspects of food. In exploring the everyday uses of food, we contribute to a wider understanding of the role of food in culturally patterned lived experience. We have argued that what people eat, how they eat, and who they eat with (Brillat-Savarin, 1826/1949) both 
locates them within specific locales (Lévi-Strauss, 1970) and connects them to wider social networks (Latour, 2005). It is in the preparation and consumption of food that cultural memories are transmitted, reproduced and renegotiated in accordance with the evolving circumstances of households. The participants in this research are constantly (re)interpreting, (dis)establishing, and re-establishing connections between themselves, material objects and traditions. In the creating and eating of specific foods people transcend time and place, render distant things proximate, reconstruct identities, and contribute towards the creation of a sense of belonging and home.

As far as the authors are aware there are no conflicts of interest, and our respective employers have no financial, commercial, legal, or professional relationship with any organization, or with the people working with them, that might influence our research.

Acknowledgements: We wish to acknowledge the Trust Waikato Student Community Grant, the Māori and Psychology Research Unit Postgraduate Research Scholarship and the University of Waikato Masters Study Award in supporting this research.

\section{References}

Belsky, D. W., Moffitt, T. E., Arseneault, L., Melchior, M. and A. Caspi, (2010). Context and sequelae of food insecurity in children's development. American Journal of Epidemiology, 172(7), 809-818. 10.1093/aje/kwq201

Blunt, A. and R. Dowling (2006). Home. New York, NY: Routledge.

Brillat-Savarin, J. A. (1826/1949). The physiology of taste, or, Meditations on transcendental gastronomy (M. F. K. Fisher, Trans.). New York, NY: The Heritage Press.

Bugge, A. B. and Almås, R. (2006). Domestic dinner: Representations and practices of a proper meal among young suburban mothers. Journal of Consumer Culture, 6(2), 203-228. 10.1177/0961463×03012001356

Caputo, L. (2011). Gender, food, and loss. Studies in Gender and Sexuality, 12(3), 179-195. 10.1080/15240657.2011.585885

Carpiano, R. M. (2009). Come take a walk with me: The "Go-Along" interview as a novel method for studying the implications of place for health and well-being. Health and Place, 15, 263-272. 10.1016/j.healthplace.2008.005.003

Cash, J. R. (2013). Performing hospitality in Moldova: Ambiguous, alternative, and undeveloped models of national identity. History and Anthropology, 24(1), 56-77. 10.1080/02757206.2012.759109

Choo, S. (2004). Eating satay babi: sensory perception of transnational movement. Journal of Intercultural Studies, 25, 203-213.

Collins, F. L. (2008). Of kimchi and coffee: globalisation, transnationalism and familiarity in culinary consumption.
Social and Cultural Geography, 9(2), 151-169.

$10.1080 / 14649360701856094$

Cook, I. (2008). Geographies of food: mixing. Progress in Human Geography, 32(6), 821-833. 10.1177/0309132508090979

Cubitt, G. (2008). History and memory. Manchester, UK: Manchester University Press.

de Solier, I. and J. Duruz (2013). Food cultures: Introduction. Cultural Studies Review, 19(1), 4-8.

DeVault, M. L. (1991). Feeding the family. Chicago, IL: University of Chicago Press.

Dodson, J. E. and C. T. Gilkes (1995). 'There's nothing like church food'. Journal of the American Academy of Religion, 63(3), 519.

Dowling, R. and E. Power (2012). Sizing home, doing family in Sydney, Australia. Housing Studies, 27(5), 605-619. 10.1080/02673037.2012.697552

Drewnowski, A. and S. E. Specter (2004). Poverty and obesity: the role of energy density and energy costs. American Journal of Clinical Nutrition, 79(1), 6-16.

Duff, C. (2012). Accounting for context: exploring the role of objects and spaces in the consumption of alcohol and other drugs. Social and Cultural Geography, 13(2), 145-159. 10.1080/14649365.2012.655765

Fortier, A.-M. (1999). Re-Membering places and the performance of belonging(s). Theory, Culture and Society, 16(2), 41-64.

Gilgen, M. (2008, 23-24 November 2007). Te whanau o te maungarongo hikoi: Māori practice in motion (3 July 2006 to 9 July 2006). In M. Levy, L. W. Nikora, B. Masters-Awatere, M. Rua and M. Waitoki (Eds.), Claiming Spaces: Proceedings of the 2007 National Mãori and Pacific Psychologies Symposium (pp. 77-82). Hamilton, NZ: Māori and Psychology Research Unit, University of Waikato.

Goody, J. (1982). Cooking, cuisine and class: A study in comparative sociology. Cambridge, UK: Cambridge University Press.

Hage, G. (1997). At home in the entrails of the West: multiculturalism, 'ethnic food' and migrant home-building. In $\mathrm{H}$. Grace, G. Hage, L. Johnson and J. Langsworth (Eds.), Home/ World: Space, community and marginality in Sydney's West. Annandale, NSW: Pluto Press.

Harper, D. (2002). Talking about pictures: A case for photo elicitation. Visual Studies, 17(1), 13-26. 10.1080/14725860220137345

Hesse-Biber, S., Leavy, P., Quinn, C. E. and J. Zoino (2006). The mass marketing of disordered eating and eating disorders: The social psychology of women, thinness and culture. Women's Studies International Forum, 29, 208-224. doi: 10.1016/j. wsif.2006.03.007

Hodgetts, D., Hayward, B. and O. Stolte (2013). Medicinal commodities and the gift of a caring mother. Journal of Consumer Culture. doi: 10.1177/1469540513498611

Hodgetts, D. J. and O. E. E. Stolte (2012). Case-based research in community and social psychology. Introduction to the special issue. Journal of Community and Applied Social Psychology, 22(5), 379-389.

Holtzman, J. D. (2006). Food and memory. Annual Review of Anthropology, 35, 361-378. 10.2307/25064929

Jansen, W. (1997). Gender identity and the rituals of food in a Jordanian community. Food and Foodways, 7(2), 87-117. 10.1080/07409710.1997.9962056

Jóhannesson, G. T. and J. O. Bærenholdt (2009). Actor-network theory/network geographies. In K. Rob and T. Nigel (Eds.), 
International Encyclopedia of Human Geography (pp. 15-19). Oxford: Elsevier.

Johnson, D., Hodgetts, D., and L. W. Nikora (2013). A humanistic approach to addressing the needs of Māori homeless people with mental health concerns. Journal of Humanistic Psychology, 53(1), 94-113. 10.1177/0022167812447297

Knepper, W. (2006). Colonization, creolization, and globalization: The art and ruses of bricolage. Small Axe(21), 70-86.

Kohn, T. (2013). Stuffed turkey and pumpkin pie: In, through and out of American contexts. Cultural Studies Review, 19(1), 50-72.

Kusenbach, M. (2003). Street phenomenology: The go-along as ethnographic research tool. Ethnography, 4(3), 455-485. $10.1177 / 146613810343007$

Landzelius, M. (2003). Commemorative dis(re)membering: Erasing heritge, spatializing disinheritance. Environment and Planning D: Society and Space, 21, 195-221. 10.1068/d286t

Latour, B. (2005). Reassembling the social. Oxford, UK: Oxford University Press.

Latour, B. (2013). Biography of an inquiry: On a book about modes of existence. Social Studies of Science, 43(2), 287-301. $10.1177 / 0306312712470751$

Lévi-Strauss, C. (1966). The savage mind. Chicago, IL: University of Chicago Press.

Lévi-Strauss, C. (1970). The raw and the cooked (J. Weightman and D. Weightman, Trans., Vol. 1). London, UK: Cape.

Levine, E. E. and M. E. Schweitzer (2015). The affective and interpersonal consequences of obesity. Organizational behavior and human decision processes: a journal of fundamental research and theory in applied psychology, 127, 66-84.

Marsden, M. (2012). Fatal embrace: trading in hospitality on the frontiers of South and Central Asia. Journal of the Royal Anthropological Institute, 18, S117-S130. 10.1111/j.14679655.2012.01767.x

Mellin-Olsen, T. and M. Wandel (2005). Changes in food habits among Pakistani immigrant women in Oslo, Norway. Ethnicity and Health, 10(4), 311-339. 10.1080/13557850500145238

Mintz, S. W. and C. M. D. Bois, (2002). The anthropology of food and eating. Annual Review of Anthropology, 31, 99-119.

Morgan, N. and A. Pritchard (2005). On souvenirs and metonymy: Narratives of memory, metaphor and materiality. Tourist Studies, 5(1), 29-53. 10.1177/1468797605062714

Myerhoff, B. (1982). Life history among the elderly: Performance, visibility and re-membering. In J. Ruby (Ed.), $A$ crack in the mirror: Reflexive perspectives in anthropology (pp. 99-117). Philadelphia, PA: University of Pennsylvania Press.

Olsen, B. (2003). Material culture after text: Re-membering things. Norwegian Archaeological Review, 36(2), 87-104.

Pickering, M. and E. Keightley (2013). Communities of memory and the problem of transmission. European Journal of Cultural Studies, 16(1), 115-131. 10.1177/1367549412457481

Ramsey, R., Giskes, K., Turrell, G. and D. Gallegos (2012). Food insecurity among adults residing in disadvantaged urban areas: potential health and dietary consequences. Public Health Nutrition, 15(02), 227-237. 10.1017/ S1368980011001996

Scrinis, G. (2008). On the ideology of nutritionism. Gastronomica, 8(1), 39-48. 10.1525/gfc.2008.8.1.39

Senauer, B., Sahn, D. and H. Alderman (1986). The effect of the value of time on food consumption patterns in developing countries: evidence from Sri Lanka. American Journal of Agricultural Economics, 68(4), 920-927.

Seremetakis, C. N. (1996). The senses still. Chicago, IL: University of Chicago Press.

Serres, M. and B. Latour (1995). Conversations on science, culture and time. Ann Arbor, MI: University of Michigan Press.

Shryock, A. (2009). Hospitality lessons: Learning the shared language of Derrida and the Balga Bedouin. Paragraph, 32(1), 32-50. 10.3366/e026483340900039x

Simmel G (1903/1964) Conflict and the Web of Group Affiliations. New York, NY: Free Press.

Simmel, G. (1910/1997). Sociology of the Meal. In D. Frisby and M. Featherstone (Eds.), Simmel on Culture, (pp130-136). London, UK: Sage.

Small, M. L. (2009). ‘How many cases do I need?’: On science and the logic of case selection in field-based research. Ethnography, 10(1), 5-38.10.1177/1466138108099586

Smith, M. L. (2006). The archaeology of food preference. American Anthropology, 108(3), 480-493.

Supski, S. (2013). Aunty Sylvie's sponge: Foodmaking, cookbooks and nostalgia. Cultural Studies Review, 19(1), 28-49.

Voicu, C. D., Gorghiu, G., Anghel, A. and L. Buruleanu (2015). Considerations related to specific topics of food science in school education. Procedia - Social and Behavioral Sciences, 205, 321-328. 10.1016/j.sbspro.2015.09.092

Webber, C. B., Sobal, J. and J. S. Dollahite (2010). Shopping for fruits and vegetables. Food and retail qualities of importance to low-income households at the grocery store. Appetite, 54(2), 297-303. 10.1016/j.appet.2009.11.015 